\title{
Strategi Pengembangan Kinerja Penyuluh Pertanian dalam Pendidikan Jarak Jauh Universitas Terbuka: Kasus Alumni UT di wilayah Serang, Karawang, Cirebon, dan Tanggamus
}

\section{(The strategies for developing performances of Agricultural Extension Agents Through distance education at UT: A Case of UT's graduates in Serang, Karawang, Cirebon, and Tanggamus)}

\author{
Nurul Huda ${ }^{1}$, Sumardjo $^{2}$, Margono Slamet ${ }^{2}$, Prabowo Tjitropranoto ${ }^{2}$ \\ ${ }^{1}$ Universitas Terbuka \\ ${ }^{2}$ Departemen Sains Komunikasi dan Pengembangan Masyarakat, FEMA IPB
}

\begin{abstract}
Performance is an implementation of work. For agricultural extension agents, performances are indicators of how well they do the job. The objectives of this research were to determine the level of performances of agricultural extention agent and factors affecting them. Data were collected in July through December 2008. A survey technique was implemented among 111 agricultural extension agents who were graduated from UT and among 88 farmers in four different locations, namely Serang, Karawang, Cirebon, and Tanggamus. By using In depth interview, a qualitative information were also used in order to elaborate the findings. Data was analyzed by using descriptive and path analysis. The findings indicated that UT's graduates had a high level in performances. Several dominant factors influenced their performances. This study suggests several strategies to increase the performances of agricultural extension agents.
\end{abstract}

(Keywords: agricultural extension agents, performances, distance education).

\section{Pendahuluan}

Keberhasilan pembangunan pertanian tidak terlepas dari peran penting penyuluh karena penyuluh merupakan pihak yang langsung berhubungan dengan pemberdayaan petani. Agar dapat melaksanakan perannya dengan baik, penyuluh harus memiliki kompetensi yang sesuai dengan kondisi dan tantangan penyuluhan saat ini. Penyuluh yang mempunyai kompetensi tinggi akan mampu menunjukkan kinerja yang baik karena kompetensi merupakan salah satu faktor yang berpengaruh terhadap kinerja penyuluh. Hal ini sesuai dengan pendapat Spencer dan Spencer (1993) yang menyatakan bahwa kompetensi dapat memperkirakan seseorang dapat menyelesaikan pekerjaannya dengan baik atau tidak. Mengingat adanya tuntutan kebutuhan petani yang tinggi, penyuluh diharapkan memiliki kinerja yang baik agar dapat memberikan layanan penyuluhan yang memuaskan kepada petani.

Kinerja adalah setiap gerakan perbuatan, pelaksanaan, kegiatan atau tindakan yang diarahkan untuk mencapai suatu tujuan atau target tertentu. Tanpa adanya kinerja berarti tidak ada upaya untuk mencapai hasil atau target dan tidak akan berpengaruh kepada hasil (Kusnadi, 2003). Kinerja yang baik sebaiknya memiliki karakteristik sebagai berikut: (1) Rasional: kinerja seharusnya diterima oleh akal sehat oleh siapapun; (2) Konsisten: kinerja yang baik seharusnya sejalan dengan nilai-nilai yang ada di dalam organisasi dan tujuan organisasi, (3) Tepat: Kinerja yang baik harus dinyatakan secara tepat dan jelas; (4) Efisien: kinerja yang baik sedapat mungkin melalui pengorbanan dana yang minim dengan

\footnotetext{
${ }^{1}$ Korespondensi Penulis: 08129575708
} 
hasil yang memuaskan, dan (5) Tertantang: kinerja yang baik seharusnya dapat menantang seseorang untuk bekerja lebih baik.

Kinerja seseorang merupakan kombinasi dari kemampuan usaha dan kesempatan yang dapat dinilai dari hasil kerjanya (Mardikanto, 1993). Kinerja merupakan catatan outcome yang dihasilkan dari fungsi pegawai tertentu Kontribusi anggota organisasi terhadap organisasinya dapat diukur dengan penilaian kinerja. Jadi, kinerja adalah fungsi dari tingkat kemampuan dan derajat motivasi.

Penilaian kinerja (performance appraisal) pada dasarnya merupakan salah satu faktor kunci. Penilaian kinerja diperlukan adanya informasi yang relevan dan reliabel tentang prestasi kerja masing-masing individu (Sulistiyani dan Rosidah, 2003).

Penilaian prestasi kerja pada dasarnya penilaian yang sistematik terhadap penampilan kerja pegawai itu sendiri dan terhadap taraf potensi pegawai dalam upaya mengembangkan diri untuk kepentingan organisasi (Martoyo, 2003). Sasaran yang menjadi objek penilaian antara lain adalah kecakapan dan kemampuan pelaksanaan tugas yang diberikan, penampilan dalam pelaksanaan tugas, cara membuat laporan atas pelaksanaan tugas, kesegaran jasmani maupun rohaninya selama bekerja.

Dari paparan tersebut dapat dikatakan bahwa kinerja penyuluh merupakan bentuk implementasi dari hasil kerja penyuluh yang dapat diukur dari keberhasilan usaha. Dengan demikian, kinerja merupakan faktor penting karena dapat menentukan keberhasilan kegiatan penyuluhan terhadap petani.

Sesuai dengan tuntutan kebutuhan petani, dalam konteks penelitian ini, hasil kerja penyuluh diukur dalam hal : (1) Penerapan Inovasi, (2) Pengembangan Usaha, (3) Pemahaman terhadap Aspirasi Petani, (4) Penerapan Azas-azas Penyuluhan, (5) Membangun jejaring kerja, dan (6) Fasilitasi Pengelolaan Keluarga.

Salah satu faktor yang mempengaruhi kualitas kinerja adalah tingkat kompetensi. Oleh karena itu, upaya peningkatan kinerja penyuluh dapat dilakukan melalui peningkatan kompetensinya. Upaya peningkatan kompetensi tersebut dapat diperoleh melalui Universitas Terbuka (UT).

UT adalah salah satu perguruan tinggi yang mengembangkan program pendidikan jarak jauh yang disesuaikan dengan kebutuhan nyata pembangunan. Selaras dengan tujuan tersebut serta adanya kebutuhan dan permintaan dari pihak yang terkait, UT telah mengembangkan program studi Agribisnis bidang minat penyuluhan dan komunikasi pertanian untuk tingkat sarjana. Program tersebut bertujuan untuk mengakomodasi kebutuhan para tugas penyuluh pertanian yang ingin mengembangkan diri namun terhambat oleh lokasi kerja mereka yang umumnya berada di pelosok desa. Dengan karakteristik UT sebagai PT jarak jauh, penyuluh yang mengikuti pendidikan di UT untuk meningkatkan kompetensinya dimungkinkan untuk dapat mengikuti pendidikan yang bermutu tanpa meninggalkan tugas dan kewajibannya sebagai penyuluh.

Kini yang menjadi permasalahan adalah belum ada informasi yang komprehensif tentang sejauhmana tingkat kinerja penyuluh setelah menyelesaikan pendidikannya di UT; faktor-faktor apa yang mempengaruhi kinerja penyuluh alumni UT.

Terkait dengan permasalahan tersebut, maka yang menjadi tujuan penelitian ini adalah: (1) Mengidentifikasi tingkat kinerja penyuluh alumni UT. (2) Mengidentifikasi faktor-faktor yang dominan mempengaruhi kinerja penyuluh. (3) Merumuskan strategi pengembangan kinerja penyuluh dalam pendidikan jarak jauh Universitas Terbuka. 


\section{Metode Penelitian}

Populasi dalam penelitian ini adalah semua penyuluh alumni UT di wilayah Serang, Karawang, Cirebon, dan Tanggamus. Respoden diambil dari seluruh populasi sejumlah 111 orang dengan menggunakan metode sensus. Penelitian ini merupakan explanatory research yang berupaya menjelaskan fenomena kompetensi penyuluh alumni UT di wilayah Serang, Karawang, Cirebon, dan Tanggamus. Untuk memperkaya hasil penelitian, 88 petani juga digunakan sebagai responden untuk melengkapi informasi serta mempertajam analisis data kuantitatif yang ada.

Pengumpulan data dilakukan dari bulan Juli sampai Desember 2008. Data primer dikumpulkan dengan menggunakan instrumen dan didukung dengan wawancara mendalam. Data sekunder diperoleh dari dokumen yang dimiliki instansi terkait. Analisis data yang digunakan adalah : (1) analisis deskriptif dan (2) analisis jalur. Data diolah dengan menggunakan SPSS versi 13.0

\section{Hasil dan Pembahasan}

\section{Tingkat kinerja penyuluh alumni UT}

Sebaran penyuluh alumni UT menurut tingkat kinerja menurut persepsi penyuluh dan petani disajikan pada Tabel 1, sedangkan sebaran rataan skornya disajikan pada Tabel 2.

Tingkat kinerja penyuluh alumni UT secara umum relatif sedang dengan rataan skor 66. Tingkat kinerja penyuluh alumni UT yang relatif sedang tersebut sejalan dengan tingkat kompetensinya yang juga relatif sedang. Hal ini sesuai dengan pendapat Spencer dan Spencer (1993) yang menyatakan bahwa kompetensi dapat memperkirakan seseorang dapat menyelesaikan pekerjaannya dengan baik atau tidak.

Secara rinci, tingkat kinerja penyuluh alumni UT relatif rendah dalam hal penerapan inovasi, pemahaman terhadap aspirasi petani, dan penerapan azas-azas penyuluhan, pengembangan usaha, dan membangun jejaring kerja. Sebaliknya dalam hal fasilitasi pengelolaan keuangan keluarga, tingkat kinerjanya relatif rendah.

Tingkat kinerja penyuluh alumni UT yang relatif sedang dalam hal penerapan inovasi, ditunjukkan oleh indikator bahwa penyuluh cukup mampu memperkenalkan dan memanfaatkan inovasi untuk tujuan penelitian. Tingkat kinerja penyuluh yang relatif sedang dalam hal pemahaman terhadap aspirasi petani ditunjukkan oleh indikator bahwa penyuluh dalam melaksanakan kegiatan penyuluhan mempunyai kepedulian yang cukup baik pada kepentingan petani. Dalam hal penerapan azas-azas penyuluhan, tingkat kinerja penyuluh alumni UT relatif sedang ditunjukkan oleh indikator bahwa dalam melaksanakan kegiatan penyuluhan, penyuluh cukup dapat menerapkan azas kerjasama, partisipatif, dan kemitraan.

Tingkat kinerja penyuluh yang relatif sedang dalam hal pengembangan usaha, menunjukkan bahwa penyuluh cukup mampu melakukan pengembangan jaringan dan pengembangan sistem agribisnis. Dalam hal membangun jejaring kerja, penyuluh menunjukkan dapat membantu petani untuk menjalin relasi, baik dengan sesama petani, pihak yang membeli hasil usahatani, penyedia saprotan, maupun dengan sumber inovasi.

Tingkat kinerja penyuluh yang relatif rendah dalam hal fasilitasi pengelolaan keuangan keluarga menunjukkan bahwa penyuluh belum dapat membantu petani untuk merencanakan dan memanfaatkan keuangan keluarga. 
Tabel 1. Sebaran Penyuluh Alumni UT berdasarkan Tingkat Kinerja menurut Persepsi Penyuluh dan Petani

\begin{tabular}{|c|c|c|c|c|c|c|c|}
\hline \multirow{3}{*}{ Jenis kinerja } & \multirow{3}{*}{ Kategori* } & \multirow{2}{*}{\multicolumn{2}{|c|}{$\begin{array}{c}\text { Persepsi } \\
\text { penyuluh } \\
(\mathrm{n}=111)\end{array}$}} & \multicolumn{4}{|c|}{ Persepsi petani } \\
\hline & & & & \multicolumn{2}{|c|}{$\begin{array}{c}\underset{(n=44)}{\operatorname{anggota} K T} \\
\end{array}$} & \multicolumn{2}{|c|}{$\begin{array}{l}\text { Bukan anggota } \\
\text { KT }(n=44)\end{array}$} \\
\hline & & $\mathrm{n}$ & $\%$ & $\mathrm{n}$ & $\%$ & $\mathrm{n}$ & $\%$ \\
\hline \multirow[t]{3}{*}{ Penerapan Inovasi (Y21) } & Rendah & 23 & 20,7 & 11 & 25,0 & 21 & 47,7 \\
\hline & Sedang & 55 & 49,5 & 18 & 40,9 & 23 & 52,3 \\
\hline & Tinggi & 33 & 29,7 & 15 & 34,1 & 0 & 0 \\
\hline \multirow[t]{3}{*}{ Pengembangan Usaha (Y22) } & Rendah & 25 & 22,5 & 29 & 65,9 & 29 & 65,9 \\
\hline & Sedang & 63 & 56,8 & 12 & 27,3 & 15 & 34,1 \\
\hline & Tinggi & 23 & 20,7 & 3 & 6,8 & 0 & 0 \\
\hline \multirow[t]{3}{*}{$\begin{array}{l}\text { Pemahaman terhadap aspirasi } \\
\text { petani (Y23) }\end{array}$} & Rendah & 25 & 22,5 & 17 & 38,6 & 36 & 81,8 \\
\hline & Sedang & 44 & 39,6 & 21 & 47,7 & 8 & 18,2 \\
\hline & Tinggi & 42 & 37,8 & 6 & 13,6 & 0 & 0 \\
\hline \multirow[t]{3}{*}{ Penerapan azas2 penyuluhan (Y24) } & Rendah & 9 & 8,1 & 17 & 38,6 & 29 & 65,9 \\
\hline & Sedang & 60 & 54,1 & 24 & 54,5 & 15 & 34,1 \\
\hline & Tinggi & 42 & 37,8 & 3 & 6,8 & 0 & 0 \\
\hline \multirow[t]{3}{*}{ Membangun jejaring kerja (Y25) } & Rendah & 40 & 36,0 & 29 & 65,9 & 39 & 88,6 \\
\hline & Sedang & 48 & 43,2 & 12 & 27,3 & 5 & 11,4 \\
\hline & Tinggi & 23 & 20,7 & 3 & 6,8 & 0 & 0 \\
\hline \multirow{3}{*}{$\begin{array}{l}\text { Fasilitasi pengelolaan keuangan } \\
\text { keluarga (Y26) }\end{array}$} & Rendah & 46 & 41,4 & 26 & 59,1 & 37 & 84,1 \\
\hline & Sedang & 37 & 33,3 & 18 & 40,9 & 7 & 15,9 \\
\hline & Tinggi & 28 & 25,2 & 0 & 0 & 0 & 0 \\
\hline \multirow[t]{3}{*}{ Kinerja Keseluruhan (Y2) } & Rendah & 17 & 15,3 & 17 & 38,6 & 34 & 77,3 \\
\hline & Sedang & 67 & 60,4 & 27 & 61,4 & 10 & 22,7 \\
\hline & Tinggi & 27 & 24,3 & 0 & 0 & 0 & 0 \\
\hline
\end{tabular}

Dari paparan pada Tabel 1, dapat dikatakan bahwa perlu ada upaya untuk meningkatkan kinerja penyuluh dalam hal penerapan inovasi, pengembangan usaha, membangun jejaring kerja, pemahaman terhadap aspirasi petani, penerapan azas-azas penyuluhan, dan fasilitasi pengelolaan keuangan keluarga, agar petani mendapatkan layanan yang lebih memuaskan dalam mengembangkan usahataninya.

Tingkat kinerja penyuluh, disamping dilihat dari persepsi penyuluh itu sendiri, juga dilihat dari persepsi petani yang mendapatkan layanan penyuluhan, baik petani yang menjadi anggota kelompok tani maupun petani yang bukan anggota kelompok tani (Tabel 1). Menurut persepsi petani yang menjadi anggota kelompok tani, tingkat kinerja penyuluh alumni UT secara umum relatif sedang dengan rataan skor 54. Sebaliknya menurut persepsi petani yang bukan menjadi anggota kelompok tani, tingkat kinerja penyuluh alumni UT tergolong rendah dengan rataan skor 48.

Mengingat petani, khususnya petani yang tidak menjadi anggota kelompok tani menilai tingkat kinerja penyuluh alumni UT tergolong rendah, maka perlu adanya upaya perbaikan kinerja penyuluh alumni UT agar petani yang merupakan sasaran penyuluhan mendapatkan layanan yang lebih baik. Upaya tersebut dapat dilakukan melalui perbaikan tingkat kompetensi penyuluh, yang difokuskan pada peningkatan pengetahuan, sikap mental, dan keterampilan penyuluh. 
Tabel 2. Sebaran Rataan Skor Kinerja Penyuluh Alumni UT menurut Persepsi Penyuluh dan Petani

\begin{tabular}{lcccccc}
\hline \multirow{2}{*}{ Jenis kinerja } & \multicolumn{9}{c}{ Persepsi } \\
\cline { 2 - 8 } & \multicolumn{2}{c}{ Penyuluh } & \multicolumn{2}{c}{$\begin{array}{c}\text { Petani } \\
\text { (anggota Kelompok Tani) }\end{array}$} & \multicolumn{2}{c}{$\begin{array}{c}\text { Petani (bukan } \\
\text { anggota } \\
\text { Kelompok Tani }\end{array}$} \\
\cline { 2 - 8 } & Rataan & Sd & Rataan & Sd & Rataan & Sd \\
\hline $\begin{array}{l}\text { Penerapan inovasi } \\
\text { Pengembangan usaha }\end{array}$ & 68 & 18 & 58 & 11 & 52 & 12 \\
$\begin{array}{l}\text { Pemahaman terhadap } \\
\text { aspirasi petani }\end{array}$ & 72 & 19 & 50 & 10 & 48 & 17 \\
$\begin{array}{l}\text { Penerapan azas2 } \\
\text { penyuluhan }\end{array}$ & 71 & 17 & 61 & 12 & 49 & 13 \\
$\begin{array}{l}\text { Membangun jejaring } \\
\text { kerja }\end{array}$ & 63 & 20 & 53 & 11 & 54 & 17 \\
$\begin{array}{l}\text { Fasilitasi pengelolaan } \\
\text { keuangan keluarga }\end{array}$ & 60 & 22 & 48 & 12 & 41 & 13 \\
Kinerja keseluruhan & 66 & 16 & 54 & 11 & 48 & 14 \\
\hline
\end{tabular}

Faktor-faktor yang dominan mempengaruhi kinerja penyuluh alumni UT

Faktor-faktor yang dominan dan secara langsung berpengaruh terhadap kinerja penyuluh secara umum adalah interaksi penyuluh dengan bahan ajar, tutorial, interaksi penyuluh dengan sejawat dalam kelompok belajar, kompetensi personal, dan kompetensi tugas, dan kompetensi sosial (Tabel 3 dan Gambar 2). Faktor-faktor tersebut (kecuali kompetensi tugas yang menunjukkan pengaruh negatif), menunjukkan pengaruh yang positif terhadap kinerja penyuluh. Dengan demikian, tingkat kinerja penyuluh alumni UT yang cenderung tinggi disebabkan oleh tingginya interaksi penyuluh dengan bahan ajar, kualitas tutorial, interaksi penyuluh dengan sejawat dalam kelompok belajar, dan kompetensi personal.

Pada Tabel 3 dan Gambar 2 diketahui bahwa umur, masa kerja, cakupan mata kuliah, media non cetak, dan kebutuhan petani menunjukkan pengaruh tidak langsung terhadap kinerja penyuluh melalui kompetensi personal. Faktor-faktor yang dominan tetapi tidak secara langsung berpengaruh terhadap kinerja penyuluh, yaitu melalui : (1) kompetensi personal adalah umur, masa kerja, cakupan mata kuliah, media non cetak, dan kebutuhan petan; (2) kompetensi tugas, adalah jabatan fungsional, tingkat motivasi, interaksi penyuluh dengan bahan ajar, dan kualitas interaksi penyuluh dengan sejawat dalam kelompok belajar; (3) kompetensi andragogik, adalah tutorial, fasilitas belajar, dan pelatihan; (4) kompetensi sosial, adalah cakupan mata kuliah, fasilitas belajar, dan pelatihan fungsional.

Motivasi belajar, tingkat interaksi penyuluh dengan bahan ajar, kegiatan tutorial, interaksi penyuluh dalam kelompok belajar, media non cetak, kompetensi personal dan kompetensi tugas menunjukkan kontribusi terbesar terhadap kinerja penyuluh. Hal ini bermakna motivasi, tingkat interaksi penyuluh dengan bahan ajar, kegiatan tutorial, interaksi penyuluh dalam kelompok belajar, media non cetak, kompetensi personal dan kompetensi tugas merupakan faktor utama yang dapat meningkatkan kinerja penyuluh. 
Tabel 3. Nilai pengaruh langsung dan tidak langsung peubah bebas terhadap kinerja penyuluh secara keseluruhan berdasarkan analisis jalur

\begin{tabular}{|c|c|c|c|c|c|c|}
\hline \multirow[t]{2}{*}{ Peubah } & \multirow{2}{*}{$\begin{array}{l}\text { Langsung } \\
\text { ke } \\
\text { kinerja } \\
\text { penyuluh }\end{array}$} & \multicolumn{4}{|c|}{ Tidak langsung melalui } & \multirow{2}{*}{$\begin{array}{l}\text { Total } \\
\text { pengaruh }\end{array}$} \\
\hline & & $\begin{array}{l}\text { Kompetensi } \\
\text { personal }\end{array}$ & $\begin{array}{l}\text { Kompetensi } \\
\text { tugas }\end{array}$ & $\begin{array}{l}\text { Kompetensi } \\
\text { Andragogik }\end{array}$ & $\begin{array}{l}\text { Kompetensi } \\
\text { Sosial }\end{array}$ & \\
\hline Umur (X11) & - & -.086 & - & - & - & -.086 \\
\hline Masa Kerja (X12) & - & .144 & - & -.029 & - & .115 \\
\hline Jabatan Fungsional (X13) & -.094 & - & .103 & - & - & .009 \\
\hline Motivasi (X14) & .109 & - & .096 & - & - & .205 \\
\hline $\begin{array}{l}\text { Interaksi dengan bahan ajar } \\
\text { (X21) }\end{array}$ & .258 & .045 & .089 & - & - & .392 \\
\hline Tutorial (X22) & .229 & - & - & .025 & - & .254 \\
\hline Mata Kuliah (X23) & -.092 & -.147 & - & - & -.053 & -.292 \\
\hline $\begin{array}{l}\text { Interaksi dengan sesama } \\
\text { penyuluh (X24) }\end{array}$ & .284 & - & .122 & - & - & .406 \\
\hline Fasilitas Belajar (X25) & -.004 & - & - & .036 & .032 & .072 \\
\hline Pelatihan (X31) & .065 & - & - & .022 & $-.036^{*}$ & .051 \\
\hline Media Cetak (X32) & .000 & .037 & -.062 & - & - & -.025 \\
\hline Media Non Cetak (X33) & .074 & - & .006 & - & - & .080 \\
\hline Kebutuhan petani (X41) & .115 & .063 & .002 & .021 & - & .201 \\
\hline Dukungan Lembaga (X42) & -.003 & - & - & - & - & -.003 \\
\hline Kompetensi personal (Y11) & .329 & - & - & - & - & .329 \\
\hline Kompetensi Tugas (Y12) & .414 & - & - & - & - & .414 \\
\hline Kompetensi andragogik (Y13) & .165 & - & - & - & - & .165 \\
\hline Kompetensi Sosial (Y14) & .187 & - & - & - & - & .187 \\
\hline
\end{tabular}

Mengingat kompetensi merupakan faktor yang dapat menunjukkan kinerja seseorang, maka dalam penelitian ini kompetensi personal dan kompetensi tugas merupakan faktor yang dapat difokuskan dalam upaya peningkatan kinerja penyuluh alumni UT.

Gambar 3. Faktor-faktor yang mempengaruhi kinerja penyuluh alumni UT

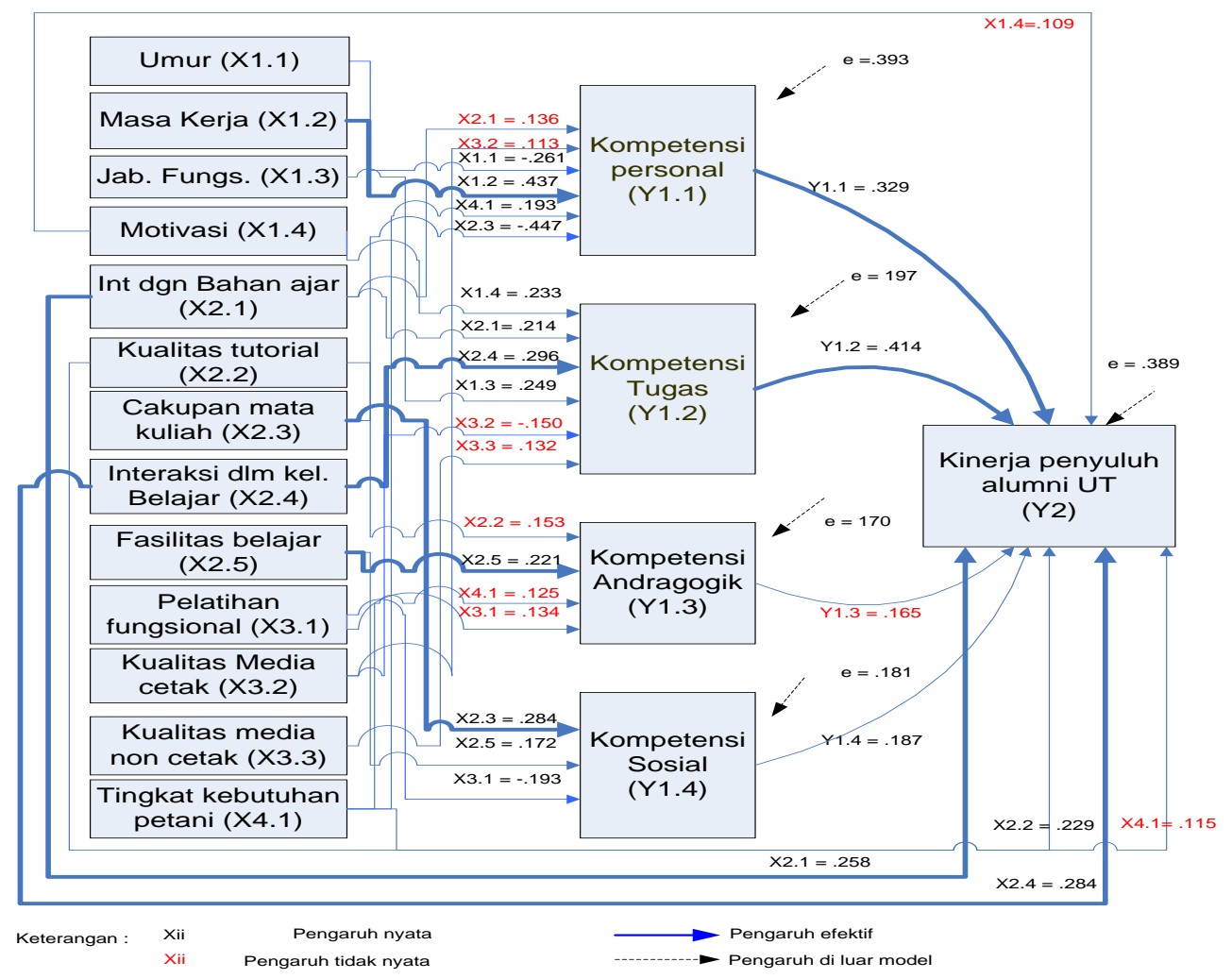


Strategi pengembangan kinerja penyuluh melalui pendidikan jarak jauh Universitas Terbuka

Strategi pengembangan kinerja penyuluh melalui pendidikan jarak jauh Universitas Terbuka dilakukan dengan tujuan untuk meningkatkan kompetensi penyuluh alumni UT sehingga penyuluh mampu menunjukkan kinerja yang lebih baik. Berdasarkan hasil penelitian ini, strategi yang dikembangkan meliputi: (1) Peningkatan kompetensi penyuluh, baik kompetensi personal maupun kompetensi tugas. Upaya peningkatan tersebut difokuskan pada peningkatan pengetahuan, sikap mental, dan keterampilan penyuluh. (2) Peningkatan kualitas pembelajaran di UT agar efektif meningkatkan kompetensi penyuluh yang selanjutnya dapat berdampak pada peningkatan kinerja penyuluh alumni UT.

\section{Kesimpulan}

Tingkat kinerja penyuluh alumni UT secara umum relatif sedang. Secara rinci, tingkat kinerja penyuluh alumni UT relatif sedang dalam hal penerapan inovasi, pemahaman terhadap aspirasi petani, penerapan azas-azas penyuluhan, pengembangan usaha, dan membangun jejaring kerja. Sebaliknya dalam hal fasilitasi pengelolaan keuangan keluarga, tingkat kinerjanya cenderung rendah.

Tingkat kinerja penyuluh alumni UT yang relatif sedang disebabkan oleh tingkat kompetensi personal dan kompetensi profesional yang juga relatif sedang.

Menurut persepsi petani yang menjadi anggota kelompok tani, tingkat kinerja penyuluh alumni UT relatif sedang, namun menurut persepsi petani yang bukan anggota kelompok tani, tingkat kinerja penyuluh alumni relatif rendah.

Strategi yang perlu dikembangkan untuk peningkatan kinerja penyuluh alumni UT adalah peningkatan kompetensi personal dan kompetensi tugas yang difokuskan pada peningkatan pengetahuan, sikap mental, dan keterampilan yang terkait dengan kepribadian (personal) yang harus dimiliki seorang penyuluh dan pengetahuan terkait dengan tugas sebagai penyuluh.

\section{Daftar Pustaka}

Bandura, A. 1986. Social Foundations of Thought and Action: A Social Cognitive Theory. New Jersey:Prentice Hall, Inc.

Mangkuprawira, S. 2004. Arti dan Beragam Aspek tentang Kompetensi. Makalah penunjang untuk lokakarya Fakultas Pertanian, IPB. 28 April 2004. Bogor.

Mardikanto, T. 1993. Penyuluhan Pembangunan Pertanian. Surakarta: Sebelas Maret University Press.

Spencer, Lyle M dan Signe M Spencer, 1993. Competence at Work: Model for Superior Performance. New York: John Wiley and Sons Inc.

[Deptan] Departemen Pertanian. 2006. Undang-undang RI No 16 tentang Sistem penyuluhan pertanian, perikanan, dan kehutanan. Departemen Pertanian. Jakarta.

[Deptan] Departemen Pertanian. 1999. Surat Keputusan Menegkowasbangpan nomor 19/KEP/MK Waspan/5/1999 tentang tugas pokok penyuluh pertanian, Departemen Pertanian, Jakarta.

[Depdiknas] Departemen Pendidikan Nasional. 2005. Undang-undang RI No 14 tentang Guru dan Dosen. Departemen Pendidikan Nasional. Jakarta.

2006. Perkembangan jumlah penyuluh pertanian. Tersedia pada can_sdm@deptan.go.ipb. Diakses pada 9 agustus 2006; Internet. 